John Pullerits MD FKCrC, Frederick A. Burtows mD FRCPC, W. Lawrence Roy MD FRCPC

\title{
Arterial desaturation in healthy children during transfer to the recovery room
}

The oxygen saturation in 71 healthy paediatric patients ( 3.5 months to 16.7 years) was measured by pulse oximetry during transfer from the operating room to the recovery room. These measurements were recorded continuously while the patients breathed room air. Of the patients studied, 28.1 per cent exhibited significan arterial desaturation of $\leq 90$ per cent. The corresponding $\mathrm{PO}_{2}$ for this saturation level is $\leq 58 \mathrm{mmHg}$. In only 45 per cent of these desaturated patients was the desaturation recognized clinically by the presence of cyanosis. Age, type of anaesthetic, the use or avoidance of narcotics, and the use of controlled or spontaneous respiration had no significant rela lionship to the incidence of desaturation. Since more than a one quarter of all patients studied desaturated significantly, and since cyunosis can be difficult to detect clinically during the transfer period, the use of supplemental oxygen during transfer should be considered by the anoesthetist at the end of every pcediaric general anaesthetic.

It is common practice in adult anaesthesia to administer supplemental oxygen to patients at the end of surgery during transfer from the operating room (OR) to the recovery area (PAR). This is, however, not common practice for healthy children, most of whom breathe room air during transfer from the OR to the PAR. During this period, close observation of patient colour and ventilation is often difficult and hypoxia and hypoventilation can occur undetected.'

Recent studies have demonstrated significant arterial desaturation in paediatric patients while they are in the PAR. ${ }^{2}$ However, the rapidity and extent of arterial

\section{Key words}

ANAESTHESIA: paediatric; OXYGEN: blood levels; MEASUREMENT TECHNIQUES: pulse oximetry.

From the Department of Anaesthesia and the Research Institute,

The Hospital for Sick Children, Toronto, Ontario.

Address correspondence 1o: Dr. John Pullerits, Department of Anaesthesia, The Hospital for Sick Children, 555 University Avenuc, Toronto, Ontario, M5G IX8. desaturation in postoperative paediatric patients breathing room air during transfer from the operating room to the PAR remains to be established. Therefore, we continuously recorded the arterial oxygen saturations in 71 healthy paediatric patients during this transfer period.

\section{Methods}

With the approval of the Human Experimentation Committee, an observer-blinded study involving 71 ASA physical status I paediatric patients scheduled for minor surgery was undertaken. Ages ranged from 3.5 months to 16.7 years (mean 5.5 years). Patients with a history of recent respiratory tract infection, cardiac or lung disease, or those with anaemia were cxcluded. All paticnts were scheduled for elective procedures. These were primarily ophthalmological procedures, hernia repairs, orthopaedic procedures or tonsil surgery. No patient had an abdominal or thoracic procedure. The patients were not premedicated. Anaesthesia was induced by inhalation agents or by intravenous thiopentone. Maintenance of anaesthesia was: inhalational with nitrous oxide, oxygen and halothane or isoflurane; intravenous with nitrous oxide, oxygen, morphine or fentanyl or a combination. Ventilation was either spontaneous or controlled. Muscle relaxation, when utilized, was provided with pancuronium or tubocurarine. At the end of the anaesthetic, all patients were given 100 per cent oxygen. Muscle relaxation, when present, was reversed with atropine and neostigmine. All patients were extubated in the operating room. Patients were either extubated before reacting to the endotracheal tube or were extubated awake. After extubation, the patient's airways were asscssed and 100 per cent oxygen was administered by face mask for three minutes before transfer to the postanaesthetic recovery room (PAR). All patients were transported on their side in a $5^{\circ}$ head down position, while breathing room air. Patients who coughed or demonstrated breath-holding during the transfer were excluded from the study.

Oxygen saturation was measured in each patient with a Nellcor N-10 (Hayward, California) battery-powered, portable pulse oximeter with attached printer ${ }^{3}$ at the following times: (1) a few minutes preoperatively in the 
TABLE Patient characteristics

\begin{tabular}{lll}
\hline & \multicolumn{2}{l}{ Number of patients } \\
\cline { 2 - 3 } Calegory & Yes & No \\
\hline Narcotics & 29 & 42 \\
Tonsillectomy & 14 & 57 \\
Spontaneous ventilation & 40 & 31 \\
Age < 3 years & 21 & \\
Age $>3$ years & 50 & \\
\hline
\end{tabular}

patient holding area while the patient was breathing room air, (2) in the operating room just before removal of the face mask, during breathing of 100 per cent oxygen, and then during transfer at, (3) 30 seconds, (4) 1 minute, (5) 1.5 minutes, (6) 2 minutes, (7) 2.5 minutes, (8) 3 minutes after removing the mask, and, (9) on arrival in the PAR. The measurements during transfer were all made while the patients were breathing room air. An arterial saturation of $\leq 90$ per cent was considered to be clinically significant. ${ }^{4}$ The attending anaesthetists were unaware of the measured oxygen saturations during the transfer period since they were not allowed to see the pulse oximeter readouts and hence relied solely on clinical signs for the detection of hypoxaemia.

After the data were determined to be normally distributed, ${ }^{5}$ statistical significance was determined using analysis of variance and the Student-Newman-Keuls multiple range test to compare the arterial saturations during the nine time periods. Arterial saturation was compared using the Student's t-test with Bonferonni correction between spontaneously breathing and ventilated patients, paticnts having tonsillectomy surgery versus other types of surgery, between patients $<3$ years of age and $>3$ years of age and between patients receiving intraoperative narcotics versus those who did not receive narcotics. The number of patients in each category is shown in the Table. Data are shown as means $\pm \mathrm{SD}$. A $p<0.05$ was accepted as indicating statistical significance.

\section{Results}

The mean age of the patients was 5.5 years (range: 0.3 to 16.7 years). The pattern of arterial oxygen saturation changes during transfer is shown in Figure 1. The mean preoperative $\left(\mathrm{F}_{1} \mathrm{O}_{2}=0.21\right)$ arterial oxygen saturation was $97.97 \pm 2.1$ per cent $)$. The arterial saturations were significantly lower $(p<0.05$ ) than preoperative values from the one minute point on during the transfer period. The lowest mean arterial saturation was $94.73 \pm 4.5$ per cent. This occurred 1.5 minutes after removal of the mask and during transfer to the PAR. Arterial oxygen saturations remained significantly lower than preoperative values until $\mathrm{O}_{2}$ was administered in the recovery room

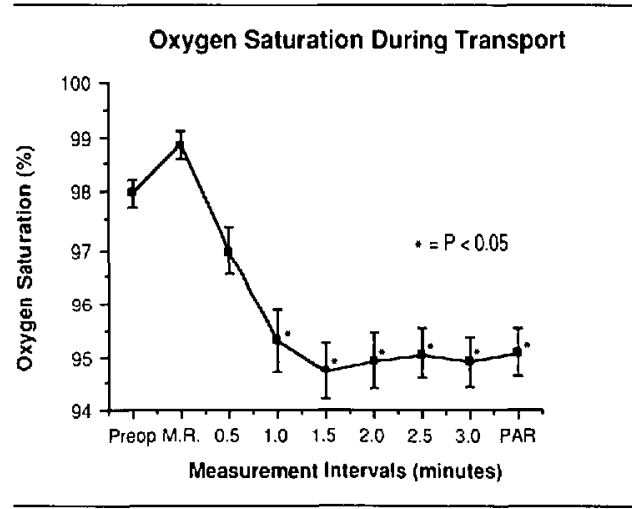

FIGURE 1 Changes in arterial oxygen saturation observed during transfer from the operating room to the PAR. Values represent the mean \pm standard deviation. Abbreviations: Preop, preoperative; MR, mask removal; PAR, postanaesthetic recovery area.

$(p<0.05)$. The mean arterial oxygen saturation immediately before the administration of oxygen in the recovery room was $95.1 \pm 3.9$ per cent. Of the 71 patients studied, 15 patients ( 21.1 per cent) desaturated to $85-90$ per cent ( $\mathrm{PO}_{2}: 50-58 \mathrm{mmHg}$ ) and five patients (seven per cent) desaturated to less than 85 per cent $\left(\mathrm{PO}_{2}:<50 \mathrm{mmHg}\right.$ ) at some time during their transfer to the recovery room, for an overall incidence of 20 out of 71 patients or 28.1 per cent (Figure 2). There were no episodes of life-threatening complications associated with desaturation in these patients. All five of the patients who desaturated to less than 85 per cent were identified clinically by the attending anaesthetists

There was no statistically significant difference between spontaneously breathing patients versus those receiving controlled ventilation, patients who received

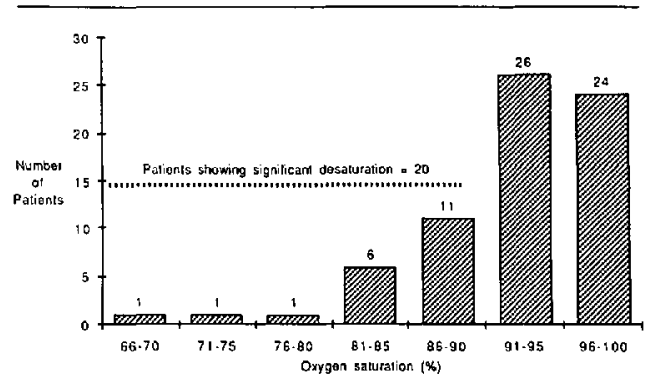

FIGURE 2 The number of patients whose lowest oxygen saluration measured during transit from OR to PAR is shown above each bar. The toral number of patients showing "significant" desaturation was 20 of 71 patients or 28.1 per cent of those studied. 
narcotics versus those who did not, patients $<3$ years of age versus those $>3$ years of age, or patients having tonsillectomies versus those having other surgeries.

\section{Discussion}

Clinically significant arterial desaturation $\left(\mathrm{SaO}_{2} \leq 90\right.$ per cent), occurted in 28.1 per cent of our healthy postoperative paediatric patients who were breathing room air during the transfer from the operating room to the PAR. This desaturation often occurred quickly and despite careful maintenance of the airway during this period. The desaturation observed in our patients could not be attributed to breathholding or coughing since these patients were excluded from the study. Diffusion hypoxia following nitrous oxide administration could not be a contributing factor since all of our patients breathed 100 per cent oxygen for three minutes at the end of the case. ${ }^{6}$ Patient age, the intraoperative use or avoidance of narcotics and the use of spontaneous versus controlled respiration had no bearing on the degree of the desaturation seen in our patients. Our findings agree with those of Motoyama and Glazener who found that patient age and duration of anaesthesia did not correlate with the degree of postoperative hypoxaemia detected in the PAR ?

Our findings are similar also to those of Tyler $e t$ al. who studied healthy adult patients during transfer to thc PAR. ${ }^{4}$ Tyler defined hypoxaemia as an arterial oxygen saturation of $\leqq 90$ per cent which corresponds to an arterial $\mathrm{PO}_{2} \leq$ $58 \mathrm{mmHg}$ and severe hypoxia as an oxygen saturation of $\leq 85$ per cent $\left(\mathrm{PO}_{2} \leq 50 \mathrm{mmHg}\right)$. By these criteria, 35 per cent of their healthy adult patients were hypoxaemic and 12 per cent severely hypoxaemic during the transfer period. In that study, postoperative hypoxaemia did not correlate with the anaesthetic agent, age, duration of anaesthesia but there was a significant correlation between hypoxaemia and obesity, a condition associated with low functional residual capacity.

Children may be predisposed to more rapid and more severe arterial desaturation than adults. They have a greater basal metabolic rate and therefore a greater oxygen requirement, in relative terms, than adults. They also have lower lung static recoil pressures and hence have more compliant thoracic walls than adults. ${ }^{8}$ As a result, their awake functional residual capacities are lower than in adults. Myotyama et al. demonstrated further reductions in FRC in children under general anaesthesia. ${ }^{9}$

Our study examined only healthy patients undergoing minor surgical procedures. We excluded all children who demonstrated irregular breathing patterns such as coughing and breathholcing during the study period. Inclusion of such patients would most likely have increased the incidence and severity of the changes in arterial saturations.
Similarly, by excluding thoracic or upper abdominal procedures which may further increase the observed falls in arterial saturation, ${ }^{10}$ we feel that this study underestimates the incidence of significant hypoxaemia that would occur in normal clinical paediatric practicc.

Our study found that 28.1 per cent of the 71 healthy children had significant arterial desaturation as detected by pulse oximetry and of these episodes, only 9 out of 20 (45 per cent) were identified clinically. Recognizing that cyanosis may be difficult to detect during the transfer period, the administration of supplemental oxygen during transfer to the recovery room should be considered at the end of every paediatric anaesthetic.

\section{References}

1 Coté CJ, Goldstein EA, Ryan JF, Coté MA. A single blinded study of pulse oximetry in children. Anesthesiology 1986; 65: A446.

2 Brown $M D$, Kallar $S K$. Hypoxemia in children following general anaesthesia in the ambulatory surgery center. Anesthesiology 1985; 63: A460.

3 Yelderman $M$. New $W$. Evaluation of pulse oxinnetry. Anesthesiology 1983; 59: 349-52.

4 Tyler IL, Tantsira B, Winter PM, Motoyama EK. Continuous monitoring of arterial oxygen saturation with pulse oximetry during transfer to the recovery room. Anesth Analg 1985; 64: $1108-12$.

5 Zar JH. Biastatistical Analysis. Second edition. PrenticeHall, Inc., Englewood Cliffs, New Jersey, 1984. pp 95-6.

6 Frumin MJ, Edelist $G$. Diffusion anoxia: a critical rcappraisal. Anesthesiology 1969; 31: 243-9.

7 Motoyama EK, Glazener CH. Hypoxemia after general anaesthesia in children. Anesth Aralg 1986; 65: 267-72.

8 Marshal BE, Wyche MQ. Hypoxemia during and after anaesthesia. Anesthesiology 1972; 37: 178-209.

9 Motoyama EK, Brinkmeyer SD, Murich RL, Walczak SA. Reduced FRC in ancsthetized infants: effect of low PEEP. Anesthesiology 1982; 57: A418.

10 Cruig $D B$. Postoperative recovery of pulmonary function. Anesth Analg 1981; 60: 46-52. 


\section{Résumé}

On a mesuré la saturation en oxygène par oxymétrie pulsative. chez 71 enfants en santé (3.5 mois à 16.7 ans), durant le transferr de la salle d" opération a la salle de réveit. Ces mesures ont été enregistrées de façon continue pendant que les patients respiraient à l'air libre. Parmi les patients étudiés, 28.1 pour cent ont démontré une dessaturation artérielle significative de $\leq$ 90 pour cent. La $\mathrm{PO}_{2}$ correspondante pour ce niveau de saturation est $\leq 58 \mathrm{mmHg}$. La dessaturation a été cliniquemen identifiée par to présence do cyanose chez seulement 45 pour cent de ces patients, L'âge, le genre d'anesthésie, lutilisation ou non de d'opiacés, et l'uilitisation de la respiration contrôlée ou spontanée n'ont pas en de relation significative avec l'incidence de la dessaturation. Puisque plus du quart des patients étudiés ont subi une dessaruration significative. et puisqu'il est difficile de détecter cliniquement la cyanose durant la périade de transfert, l"utilisation d'oxygène supplémentaire devrait être prise en considération par l"anesthésiste à la fin de chaque anesthêsie générale en pédiatrie. 